outdoor pollution mixture. Ozone in England does not seem to play a role in lung function.

Previous studies do not provide enough evidence to relate the effects of air pollution conclusively to one or the other specific spirometric measures, although there are some indications of larger effects on the markers of the small airways. ${ }^{4}$ Forbes et al provide data only on $\mathrm{FEV}_{1}$ and the $\mathrm{FEV}_{1} / \mathrm{FVC}$ ratio, showing no association for the ratio after adjusting for smoking and social class. Larger misclassification in the measurement of FVC than $\mathrm{FEV}_{1}$ in the general population studies may explain these results in part.

The larger size and improved exposure assessment in the study of Forbes et al reinforce the knowledge of a deleterious effect of current levels of air pollution on lung health in Europe. However, the cross-sectional nature of these studies does not solve important questions regarding the most relevant age period and exposure time windows of susceptibility. It is impossible to know if the effects on the lung function level in adulthood reflect growth deficits experienced during childhood and whether these subjects entered the lung function decline phase with a reduced lung function. The largest effects observed by Forbes et al were among the oldest people (>75 years). Nevertheless, this does not imply an effect during the decline phase since it could result from a cohort effect because of higher historical air pollution levels for this age group. It is possible that air pollution behaves like smoking in adulthood, which accelerates lung function decline, and that changes in smoking resulted in changes in the slope of decline. In any case, there is a need to extend follow-up studies to children and to perform large follow-up studies through to adolescence in order to quantify the magnitude of the effect of air pollution in accelerating lung function decline not only for a better knowledge of the origins of COPD, but also to assess the population impact of air pollution and the potential consequences of its reduction.

Competing interests: None declared.

Thorax 2009;64:645-646. doi:10.1136/thx.2009.115071

\section{REFERENCES}

1. Pope CA III, Dockery DW. Health effects of fine particulate air pollution: lines that connect. J Air Waste Manag Assoc 2006;56:709-42.
2. Romieu I, Castro-Giner F, Künzli N, et al. Air pollution oxidative stress and dietary supplementation: a review. Eur Resp J 2008;31:179-97.

3. Götschi T, Heinrich J, Sunyer J, et al. Long-term effects of ambient air pollution on lung function: a review. Epidemiology 2008;19:690-701.

4. Downs SH, Schindler C, Liu LJ, et al. Reduced exposure to PM10 and attenuated age-related decline in lung function. N Engl J Med 2007;357:2338-47.

5. Ackermann-Liebrich U, Leuenberger P, Schwartz J, et al. Lung function and long term exposure to air pollutants in Switzerland. Study on air pollution and lung diseases in adults (SAPALDIA) team. Am J Respir Crit Care Med 1997;155:122-9.

6. Schikowski T, Sugiri D, Ranft U, et al. Long-term air pollution exposure and living close to busy roads are associated with COPD in women. Respir Res 2005; 6:152

7. Forbes LJL, Kapetanakis V, Rudnicka AR, et al. Chronic exposure to outdoor air pollution and lung function in adults. Thorax 2009:64:657-63.

8. Hertel 0, Hvidberg M, Ketzel M, et al. A proper choice of route significantly reduces air pollution exposure-a study on bicycle and bus trips in urban streets. Sci Total Environ 2008;389:58-70.

9. Forastiere F, Stafoggia M, Tasco C, et al. Socioeconomic status, particulate air pollution, and daily mortality: differential exposure or differential susceptibility. Am J Ind Med 2007;50:208-16.

10. Généreux M, Auger N, Goneau M, et al. Neighbourhood socioeconomic status, maternal education and adverse birth outcomes among mothers living near highways. J Epidemiol Community Health 2008;62:695-700.

11. Sunyer J, Zock JP, Kromhout $\mathrm{H}$, et al. Lung function decline, chronic bronchitis and occupational exposures in young adults. Am J Respir Crit Care Med 2005;172:1139-45.

\title{
Can traffic-related air pollution cause asthma?
}

\section{John R Balmes}

Traffic-generated pollution contains particles and gases (eg, oxides of nitrogen) that are known to have health effects. ${ }^{1}$ Concentrations of pollutants emitted by motor vehicles are highest within $150 \mathrm{~m}$ of roadways and remain raised up to $300 \mathrm{~m}$ from roadways, but fall off markedly beyond that range. ${ }^{2}$ Exposure to the mixture of traffic-generated pollutants may be more relevant to human health than exposure to any single ambient air pollutant, making epidemiological investigations of traffic effects a key component of research into the public health impact of air pollution. However, assessment of exposure to traffic-related air pollution can be problematic. Exposure to traffic can be estimated with complex

Correspondence to: Dr J R Balmes, Department of Medicine, University of California, San Francisco and School of Public Health, University of California, Berkeley, California, USA; john.balmes@ucsf.edu dispersion models of pollutants from local freeway and non-freeway sources, but the data inputs required for such modelling are not always available. A frequently used simpler approach has been to estimate residential distance to roadways.

A number of studies have found an increased prevalence of asthma or asthma symptoms in children who live near roadways with high traffic counts. ${ }^{4-8}$ One large British study that focused on traffic within $150 \mathrm{~m}$ of children's homes found a gradient in risk that increased markedly with decreasing residential distance to a main road. ${ }^{7}$ A large study in southern California showed an increased prevalence of asthma and wheeze in children living within $75 \mathrm{~m}$ of a major roadway. ${ }^{9}$ Another study by Jerrett et al that analysed data from the same southern California cohort was able to demonstrate an association between the incidence of asthma and exposure to traffic-related pollution. ${ }^{10}$ A recent review summarised the evidence for traffic pollution as a risk factor for both asthma exacerbation and onset as strong. ${ }^{11}$

In contrast to the relatively rich literature for children, little has been published on the effects of traffic-related pollution on asthma in adults. Although several previous studies in adults with asthma have found that exposure to traffic-as measured by distance of residence from nearest major roadway-was associated with asthma symptoms, health care utilisation or decreased lung function, ${ }^{12-14}$ the study by Künzli and colleagues ${ }^{15}$ reported in this issue of Thorax is the first to show convincing evidence that exposure to traffic-related particulate matter increases the risk of adult-onset asthma (see page 664). When the paper by Künzli et al is taken together with the study by Jerrett et al, ${ }^{10}$ we now have evidence in both children and adults that traffic-related pollution can cause as well as exacerbate asthma.

Given the robust effects observed on asthma outcomes in other studies of both children and adults, it is somewhat surprising that distance to roadway was not associated with the risk of new-onset asthma in over 2700 non-smoking Swiss 
adults in the analysis by Künzli et al. ${ }^{15}$ The authors speculate that they did not find an effect of distance to roadway because their study design was longitudinal, and this variable did not change over time for most subjects. Moreover, they contend that the modelled traffic-related particulate matter exposures which they assigned to their subjects captured the spatial and temporal heterogeneity of individual exposures better than can be achieved with distance to roadway metrics. They suggest that this greater heterogeneity of exposure allowed their analysis to achieve statistical significance despite the relatively small number of new cases of asthma in the SAPALDIA cohort. Similar reasoning can be applied to the study by Jerrett et al which captured spatial heterogeneity in traffic exposures by using nitrogen dioxide concentrations measured immediately outside the children's homes as a proxy for the traffic-related pollution mixture. $^{10}$

Perhaps the greatest research challenge regarding the impact of traffic-related pollution on asthma is to determine what specific constituents of the mixture are responsible for the observed effects. While diesel exhaust particles have clearly been shown to induce both cytotoxic and immune adjuvant responses in toxicological studies $^{16}$ as well as acute lung function decrements in subjects with asthma, ${ }^{17}$ it has been difficult to distinguish diesel effects from those of other components of the traffic mixture in epidemiological studies, largely due to an inability to assess exposure properly. Until we develop better exposure assessment methods, we will be unable to meet this challenge. Without good data about the causative agents in the traffic pollution mixture, our ability to control exposures to protect the health of people with asthma will continue to be handicapped.

Competing interests: None.

Thorax 2009;64:646-647. doi:10.1136/thx.2009.116418

\section{REFERENCES}

1. Bernstein JA, Alexis N, Barnes $\mathrm{C}$, et al. Health effects of air pollution. J Allergy Clin Immunol 2004;114:1116-23

2. Gilbert NL, Goldberg MS, Beckerman B, et al. Assessing spatial variability of ambient nitrogen dioxide in Montreal, Canada, with a land-use regression model. J Air Waste Manag Assoc 2005;55:1059-63.

3. Zhu Y, Hinds WC, Kim S, et al. Concentration and size distribution of ultrafine particles near a major highway. J Air Waste Manag Assoc 2002;52:1032-42.

4. Morris SE, Sale RC, Wakefield JC, et al. Hospita admissions for asthma and chronic obstructive airways disease in east London hospitals and proximity of residence to main roads. J Epidemiol Community Health 2000;54:75-6.

5. Nicolai T, Carr D, Weiland SK, et al. Urban traffic and pollutant exposure related to respiratory outcomes and atopy in a large sample of children. Eur Respir $J$ 2003;21:956-63.
6. van Vliet $\mathbf{P}$, Knape M, de Hartog J, et al. Motor vehicle exhaust and chronic respiratory symptoms in children living near freeways. Environ Res 1997:74:122-32.

7. Venn AJ, Lewis SA, Cooper $\mathrm{M}$, et al. Living near a main road and the risk of wheezing illness in children Am J Respir Crit Care Med 2001;164:2177-80.

8. Zmirou D, Gauvin S, Pin I, et al. Traffic related air pollution and incidence of childhood asthma: results of the Vesta case-control study. J Epidemiol Community Health 2004;58:18-23.

9. McConnell R, Berhane K, Yao L, et al. Traffic, susceptibility, and childhood asthma. Environ Health Perspect 2006;114:766-72.

10. Jerrett M, Shankardass K, Berhane K, et al. Traffic related air pollution and asthma onset in children: a prospective cohort study with individual exposure measurement. Environ Health Perspect 2008;116:1433-8.

11. Salam MT, Islam T, Gilliland FD. Recent evidence for adverse effects of residential proximity to traffic sources on asthma. Curr Opin Pulm Med 2008;14:3-8.

12. Meng YY, Wilhelm M, Rull RP, et al. Traffic and outdoor air pollution levels near residences and poorly controlled asthma in adults. Ann Allergy Asthma Immunol 2007:98:455-63.

13. Lwebuga-Mukasa JS, Oyana T, Thenappan A, et al. Association between traffic volume and health care use for asthma among residents at a USCanadian border crossing point. J Asthma 2004;41:289-304.

14. Balmes JR, Earnest G, Katz PP, et al. Exposure to traffic: lung function and health status in adults with asthma. J Allergy Clin Immunol 2009;123:626-31.

15. Künzli N, Bridevaux PO, Liu L-JS, et al. Traffic-related air pollution correlates with adult-onset asthma among never-smokers. Thorax 2009;64:664-70.

16. Riedl M, Diaz-Sanchez D. Biology of diesel exhaust effects on respiratory function. J Allergy Clin Immunol 2005;115:221-8.

17. McCreanor J, Cullinan P, Nieuwenhuijsen MJ, et al. Respiratory effects of exposure to diesel traffic in persons with asthma. N Engl J Med 2007;357:2348-58.

\section{Pulmonary infection in Wegener's granulomatosis and idiopathic pulmonary fibrosis}

\section{Nicholas Kim Harrison}

Friederich Wegener's original paper "On generalised septic vessel disease" suggests he thought it likely there was an infectious cause for the condition which now bears his eponym. ${ }^{1}$ The characteristic pathological features of Wegener granulomatosis (WG) are: a necrotising granulomatous inflammation of the respiratory tract with vasculitis affecting both arteries and veins; focal necrotising glomerulonephritis; and a varying degree of systemic vasculitis-the so-called "Wegener's triad". 2 The granulomatous

Correspondence to: Dr Nicholas Kim Harrison, School of Medicine, Swansea University, Swansea, UK; Kim. Harrison@swansea-tr.wales.nhs.uk inflammation is conspicuous for the absence of any obvious microorganism, although granulomatous infections can sometimes be misdiagnosed as WG. ${ }^{3}$ During the 70 years since Wegener's description there have been some remarkable advances in both the diagnosis and treatment of this condition and in our understanding of its pathogenesis. However, the precise nature of the initiating factor(s) remains elusive.

What we do know is that there is a strong association between WG and the human leucocyte antigen (HLA)DPB1*0401 allele, suggesting that there is an inherited predisposition for the condition. ${ }^{4}$ Interestingly, there is also an association with $\alpha-1$ antitrypsin deficiency. ${ }^{5}$ We also know that virtually all patients who subsequently develop the systemic disease have circulating antineutrophil cytoplasmic antibodies (ANCAs) and these are mainly directed against proteinase-3 (PR3), the so-called "Wegener's autoantigen"-a serine protease which regulates cell proliferation, differentiation and death. ${ }^{6}$ This antibody has proved to be a useful biomarker for the diagnosis of $\mathrm{WG}^{78}$ although less so for the likelihood of relapse. ${ }^{9}$ Furthermore, our increasing knowledge of its biological properties has provided new insights into the pathogenesis of WG. Specifically, whilst PR3 is the target antigen for ANCAs, the observation that elevated levels of PR3 at sites of granulomatous inflammation correlate with increased tumour necrosis factor $\alpha(\mathrm{TNF} \alpha)$ has led to the hypothesis that PR3 is directly involved in the modulation of cytokines associated with an aberrant immune response (see Csernok et a ${ }^{10}$ for a review).

Following tissue injury, increased levels of PR3, released from activated or dying neutrophils, might act as a danger/alarm 